\title{
A Pesquisa Geolinguística em Áreas Indígenas Brasileiras: desafios e estratégias
}

\author{
Abdelhak RAZKY* \\ Regis José da Cunha GUEDES** \\ Eliane Oliveira da COSTA***
}

\begin{abstract}
* Doutorado em Linguística pela Université de Toulouse Le Mirail (1992). Pós-doutorado na Université de Toulouse Le Mirail. Atualmente é Professor Associado Nível 4 da Universidade Federal do Pará, em exercício no Departamento de Línguas Estrangeiras e Tradução da Universidade de Brasília. Bolsista de produtividade em pesquisa do CNPq - Nível 2. Contato: arazky@gmail.com.

** Mestrado (2012) e Doutorado (2017) em Letras - Estudos Linguísticos pela Universidade Federal do Pará. Professor da Universidade Federal Rural da Amazônia, campus de Tomé-Açu. Contato: regisbspaz@gmail.com.

*** Mestrado em Linguística pela Universidade Federal do Pará (2012). Doutoranda em Letras - Estudos Linguísticos na Universidade Federal do Pará. Contato: elianecosta21@yahoo.com.br.
\end{abstract}

\section{Resumo:}

Este artigo reflete sobre questões teórico-metodológicas envolvidas no eixo de pesquisa Atlas Linguístico do Português em Áreas Indígenas (ALiPAI) do projeto GeoLinTerm coordenado por Abdelhak Razky, na UFPA/UnB. Os primeiros resultados do ALiPAI fazem parte da tese de doutoramento de Guedes (2017), que mapeou o perfil geossociolinguístico do português em contato com línguas tupí-guaraní em áreas indígenas do Pará e Maranhão. As primeiras experiências na pesquisa de campo geolinguística em áreas indígenas brasileiras proporcionaram uma confluência de metodologias de pesquisa, especialmente da Geossociolinguística (RAZKY, 1998), da Dialetologia Pluridimensional e Relacional (THUN, 1998) e da Linguística Antropológica (RODRIGUES; CABRAL, 2012). Foram selecionados dez colaboradores em cada um dos cinco pontos de inquérito investigados (Suruí Aikewára, Asuriní do Tocantins, Tembé, Guajajára e Guaraní Mbyá). Foram aplicados os questionários desenvolvidos pelo Comitê Nacional do Atlas Linguístico do Brasil (2001): Questionário Fonético-Fonológico (QFF) e Questionário Semântico-Lexical (QSL). A aplicação dos questionários foi adaptada, com a inclusão da solicitação da correspondência em língua indígena para cada umas das respostas obtidas em português. Além desses, foram aplicados um QFF Complementar e um Questionário Sociolinguístico. O artigo reflete também sobre as adaptações necessárias realizadas na metodologia da pesquisa geolinguística, para dar conta das características geossociolinguísticas das comunidades-alvo do ALiPAI.

Palavras-chave:

Pesquisa geolinguística. Geossociolinguística. Áreas indígenas.

Signum: Estudos da Linguagem, Londrina, v. 21, n. 1, p. 126-138, abr. 2018 


\section{A Pesquisa Geolinguística em Áreas Indígenas Brasileiras: desafios e estratégias}

Abdelhak Razky; Regis José da Cunha Guedes; Eliane Oliveira da Costa

\section{INTRODUÇÃO}

No âmbito do desenvolvimento dos estudos geolinguísticos no Brasil, observa-se que houve grande avanço, tanto do ponto de vista teórico quanto metodológico. Essa realidade está descrita na literatura em diversos textos que, por exemplo, distinguem as fases dos estudos dialetais com base nas pesquisas realizadas em forma de atlas linguísticos e monografias.

Esses trabalhos vêm propiciando a descrição do português brasileiro, todavia, sem considerar alguns espaços sociolinguísticos, o que motiva a expansão do fazer geolinguístico para que se tenha uma visão mais real do português brasileiro (PB), como língua falada em um Brasil cada vez mais integrado às novas tecnologias e caracterizado pela diversidade linguística.

Nesse contexto, o grupo de pesquisadores do projeto Geossociolinguística e Socioterminologia (GeoLinTerm) procurou avançar em suas perspectivas de estudo com o desenvolvimento do projeto Atlas Linguístico do Português em Áreas Indígenas (ALiPAI), que tende a ampliar os horizontes da pesquisa geolinguística ao focalizar áreas indígenas brasileiras, num primeiro momento, nos estados do Pará, Maranhão, Amapá e Amazonas.

Sobre a relação do português com as línguas indígenas, é importante assinalar que "o estudo da possível influência fonológica e gramatical de línguas indígenas no português brasileiro deve ser feito não apenas com base em um bom conhecimento da língua ou das línguas indígenas envolvidas, mas também levando em conta os dialetos particulares do português brasileiro" e que "até agora não temos estudos conjugando conhecimento de ambos, as línguas indígenas e os dialetos do português brasileiro" (RODRIGUES, 2014, p. 11, tradução nossa).

O ALiPAI, então, pretende preencher essa lacuna no contexto dos estudos geolinguísticos e, como todo projeto pioneiro, tem apresentado uma série de questões teóricometodológicas, as quais são objeto deste artigo, que se estrutura em quatro sessões: (i) tipologias de pesquisa de campo na dialetologia tradicional e na dimensão geossociolinguística; (ii) os conceitos de isoglossa e agrupamento e suas implicações para pesquisa de campo; (iii) a pesquisa de campo em áreas monolíngues e bilíngues/plurilíngues; e (iv) perspectivas para a pesquisa de campo em áreas indígenas, seguida das considerações finais. 


\section{Tipologias de Pesquisa de Campo na Dialetologia Tradicional e na Dimensão Geossociolinguística}

Na dialetologia tradicional, a metodologia da pesquisa de campo já estava baseada no tripé rede de pontos-informantes-questionários. Na dimensão geossociolinguística, em se tratando da rede de pontos e do uso de questionários, observa-se uma continuidade dessas práticas; todavia, têm sido feitas algumas adaptações metodológicas, especialmente na diversificação e aplicação dos questionários. Por outro lado, no que se refere ao perfil do informante da pesquisa, a abordagem dos estudos geossociolinguísticos previu uma ampliação do campo de observação desse constituinte metodológico.

$\mathrm{Na}$ dialetologia tradicional, o informante normalmente requerido era, segundo Zágari (1998, p. 36), denominado como HARAS ("homem, adulto, rurícola, analfabeto e sedentário"). Esse perfil foi eleito no intuito de se registrar as variantes mais "preservadas" da língua em um determinado espaço. Contudo, em vista das rápidas mudanças observadas na sociedade, especialmente a partir do século XX, no qual se testemunhou um crescimento acelerado das zonas urbanas (êxodo rural), motivado pela busca de melhores condições de emprego, impõe-se uma diferente perspectiva. Nesse contexto, surgiram os primeiros estudos na área da dialetologia urbana e da sociolinguística, que objetivaram investigar as novas configurações linguísticas da variação nesse novo contexto social, no qual o perfil do informante HARAS tornou-se obsoleto.

Outra diferença observada nesse contexto diz respeito ao número de informantes considerados por ponto de inquérito. Nos estudos dialetológicos tradicionais, adotava-se normalmente um ou dois informantes por ponto, o que tem constituído, historicamente, motivo de críticas à metodologia geolinguística, que por muito tempo esteve focada no estudo da variação diatópica, privilegiando assim a ampliação do número de pontos de inquérito, em detrimento do de informantes por ponto. Com o surgimento dos estudos dialetológicos modernos, a partir da influência da Sociolinguística, na segunda metade do século XX, viu-se uma ampliação desse número de informantes para dois ou quatro por localidade, motivada pelo interesse dos dialetólogos em mapear as variáveis sociais: diagenérica, diageracional etc. Contudo, esse número ainda é considerado baixo se comparado à amostra de informantes tratados em boa parte dos estudos sociolinguísticos. Objetivando minimizar ainda mais essa característica, estudos da moderna dialetologia ampliaram para oito o número de informantes, como no caso do ALiB (CARDOSO et al., 2014) nas capitais brasileiras, com a consideração da variável diastrática (escolaridade).

No âmbito dos estudos geossociolinguísticos, como o realizado na tese de doutoramento de Guedes (2017), buscou-se ampliar ainda mais esse número de informantes. Esse estudo previu o mapeamento da fala de dez informantes por ponto de inquérito, com a inclusão (inédita) de duas crianças entre os informantes, escolha que foi motivada pela natureza da pesquisa realizada, que versou sobre a vitalidade das línguas indígenas e da variação do português falado em áreas indígenas brasileiras. 


\section{Os Conceitos de Isoglossa e Agrupamento e suas Implicações para Pesquisa de}

CAMPO

Nas pesquisas na área da dialetologia tradicional, desde meados do século XIX, os dialetólogos estavam preocupados em descrever a variação diatópica das línguas, especialmente delimitar os limites geográficos entre as línguas, dialetos e/ou falares de uma determinada região. Daí surgiu a concepção de isoglossa como uma linha imaginária traçada em um mapa, no intuito de estabelecer os limites geográficos dos fenômenos linguísticos.

As isoglossas podem ser classificadas segundo a natureza do fenômeno linguístico mapeado: as isoléxicas, que delimitam a variação lexical em uma determinada região; as isófonas que, por sua vez, referem-se à variação fonética etc.

Essa técnica de representação refletia suficientemente a configuração da distribuição geográfica dos fenômenos linguísticos em um território. Tratava-se de um momento na história da humanidade em que as distâncias e os acidentes geográficos (mares, rios, montanhas etc.) e o clima (geada, calor do deserto etc.) realmente isolavam comunidades, ou pelo menos dificultavam a frequência da comunicação entre as pessoas, o que, como é sabido, é um fator que influencia diretamente a variação linguística diatópica.

Contudo, a concepção de linhas isoglossas tem se tornado obsoleta para a representação da realidade da variação linguística, uma vez que a homogeneidade que essas linhas imaginárias se propunham a representar tem se tornado, cada vez mais, dados históricos. Isso tem se dado em função das grandes transformações por que passou a sociedade, cada vez mais globalizada, especialmente com a revolução nas comunicações e nos transportes ocorridos a partir do século XX.

O encurtamento das distâncias entre as populações é uma característica da contemporaneidade, fruto, por um lado, do desenvolvimento de meios de transporte mais eficientes, como automóveis, trens e aviões, e por outro, da democratização do acesso aos meios de comunicação como o rádio, a televisão e, mais recentemente, a internet e a telefonia celular, que propiciaram, por sua vez, o surgimento das redes sociais, que conjugam várias dessas tecnologias.

Nesse contexto em que a comunicação entre as pessoas é intensa, observa-se uma diluição das fronteiras geolinguísticas, outrora representadas pelas isoglossas, especialmente nas regiões mais urbanizadas e com maior acesso a esses meios de comunicação e transporte.

No âmbito dos estudos geossociolinguísticos, a partir de nossos estudos em Guedes (2012) e Razky e Guedes (2015), que mapearam a variação lexical nos dados do Atlas Léxico Sonoro do Pará (ALeSPA), desenvolvemos o conceito de agrupamentos lexicais diatópicos, ao observar que as lexias registradas sobre determinados itens estudados se agrupavam em regiões específicas do território paraense, na forma de macroagrupamentos e de microagrupamentos que formam intersecções espaciais, como se pode ver na Figura 1. 
Figura 1 - Agrupamentos lexicais nos dados do ALeSPA

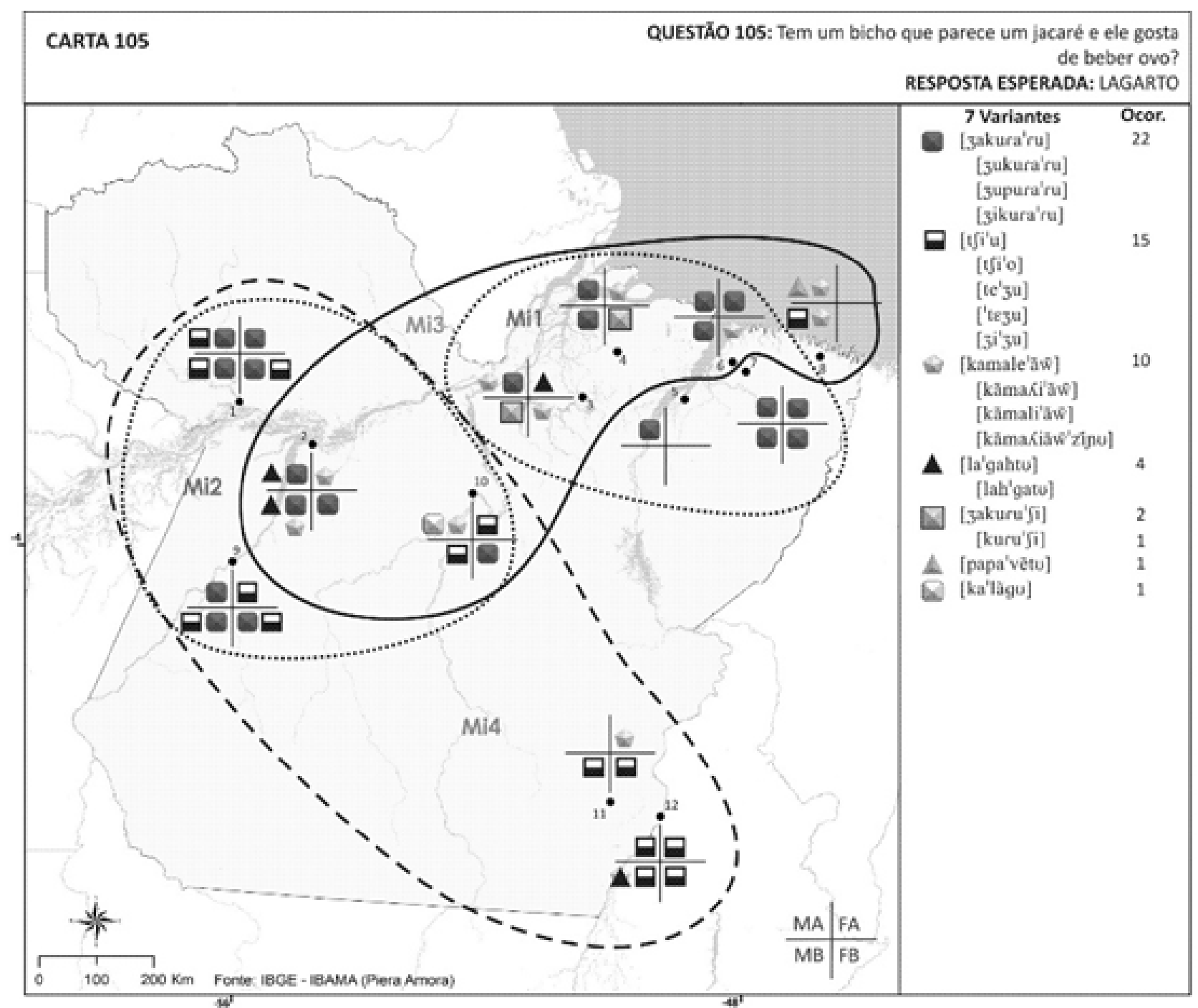

Fonte: Razky e Guedes (2015).

A distribuição diatópica das variáveis lexicais apresentadas na Carta 105 (figura 1) permitiu circunscrever agrupamentos lexicais diatópicos no espaço geográfico paraense. Esses agrupamentos representam a predominância de algumas lexias em determinados espaços geográficos em relação a outros, nos quais ou não se tem ocorrências das lexias mapeadas ou elas ocorrem com menor incidência. Como se pode observar na Figura 1, o agrupamento Mi4 apresenta a zona de predominância da lexia tiú no território mapeado; todavia, a lexia foi registrada também no ponto de inquérito 8 . Situação similar à do agrupamento $M i 3$, que circunscreve a área de predominância da lexia camaleão, lexia esta que obteve também um registro no ponto 11. É justamente essa representação da diluição das fronteiras rígidas propostas pelas isoglossas que torna a noção de agrupamento mais fiel à realidade da variação dos fenômenos linguísticos no espaço geográfico.

Entendemos que essa configuração geográfica mapeada reflete a existência passada de zonas isoléxicas no território paraense. Essa configuração, por sua vez, está relacionada 
às formas de povoamento da região. Porém, a rigidez dos limites geográficos foi se diluindo em função dessa mesma história do povoamento da região, que se deu por diversos fluxos migratórios ocorridos em épocas distintas, desde os primeiros habitantes do território (os indígenas de diversas etnias que para lá migraram por séculos) até os diferentes momentos históricos da ocupação da região amazônica por não indígenas (europeus e caboclos).

Descrevendo-se a variação lexical do português falado na região por meio do conceito de agrupamentos lexicais diatópicos, avaliamos ter conseguido representar de forma mais adequada a realidade dos fatos linguísticos estudados, uma vez que a homogeneidade diatópica pretendida no fazer das isoglossas realmente não corresponde mais à realidade da região, se é que em algum momento essa homogeneidade foi algo diferente de um mito.

\section{A Pesquisa de Campo em Áreas Monolíngues e Bilíngues/Plurilíngues}

O estudo realizado por Guedes (2017) - sobre o português falado em áreas indígenas dos estados do Pará e Maranhão - possibilitou uma reflexão singular sobre a multiculturalidade das áreas indígenas brasileiras. Como esse é um campo novo no âmbito dos estudos geolinguísticos, tratar da diversidade de línguas faladas pelos povos indígenas das áreas indígenas estudadas (o português e as línguas indígenas) nos proporcionou repensar as metodologias da pesquisa de campo na área de geolinguística. Tratou-se de um encontro de tradições metodológicas distintas: os estudos da Geossociolinguística e da Dialetologia Pluridimensional (ocupados principalmente com a variação em áreas monolíngues) e os da Linguística Antropológica (que tradicionalmente tem estudado as línguas faladas por comunidades tradicionais, por vezes áreas bilíngues e até plurilíngues).

A crescente expansão dos estudos geolinguísticos, especialmente a partir da perspectiva da Geolinguística Pluridimensional e Contatual (THUN, 1998), levou à criação de projetos de atlas linguísticos no Brasil que objetivam o mapeamento de mais de uma língua, como ocorre nas regiões de fronteira e nas comunidades em que há contato de falantes de línguas diferentes no território brasileiro (GUEDES, 2017, p. 78).

Ao propor a realização da pesquisa em sua tese, Guedes (2017) retoma a assertiva de Thun (2014) de que, nas pesquisas geolinguísticas no Brasil, a exemplo da metodologia adotada na pesquisa de campo do projeto ALiB, não se pergunta sobre o conhecimento lateral de uma língua indígena. Os dados são tratados como se o Brasil fosse um país monolíngue, e não é. Atualmente, dentro dos limites geográficos do Brasil são faladas cerca de 180 línguas indígenas (RODRIGUES, 2006), que coexistem em situações diversas de contato. A partir dessa e de outras questões que surgiram no transcorrer da pesquisa de campo, a metodologia utilizada na pesquisa nas áreas indígenas precisou de algumas adaptações, expostas na seção seguinte. 


\section{Perspectivas para a Pesquisa de Campo em Áreas Indígenas}

A tese de doutoramento defendida por Guedes (2017) constituiu um primeiro passo da realização do projeto ALiPAI ${ }^{1}$. Este projeto é pioneiro, uma vez que se propõe mapear o português falado em áreas indígenas no território brasileiro, tema que não foi objeto de estudo da Geografia Linguística no Brasil até o presente momento. Os atlas linguísticos estaduais, regionais e de pequenos domínios já elaborados, assim como o Atlas Linguístico do Brasil, não incluíram o mapeamento do português falado em áreas indígenas em seu escopo, seja por opções e/ou restrições metodológicas dos projetos, ou pelas dificuldades de acesso a essas áreas.

O projeto $\mathrm{ALiPAI}^{2}$ tem a perspectiva do preenchimento dessa lacuna. Nessa primeira etapa, objetivou-se identificar, analisar e mapear o português em contato com línguas indígenas de cinco etnias dos estados do Pará e do Maranhão, com vistas à construção de um banco de dados que forneça informações sobre a variação fonética e lexical do português em situações de contato linguístico com línguas indígenas dos ramos um e quatro da Família Tupí-Guaraní, quais sejam: Guaraní Mbyá, Suruí Aikewára, Asuriní do Tocantins, Tembé e Guajajára.

Nessas primeiras experiências do fazer da pesquisa de campo em áreas indígenas, vimo—-nos diante de situações que constituíram verdadeiros desafios metodológicos. Como exemplos disso pode-se destacar: a necessidade de coletar dados em localidades de difícil acesso (foram utilizados os meios de transporte terrestre, aquático e aéreo); a distância das terras indígenas em relação aos centros urbanos; as condições das estradas, que no "inverno amazônico" ficam praticamente intrafegáveis; a necessidade de autorização da FUNAI e/ou das lideranças indígenas para se ter acesso às terras indígenas ${ }^{3}$, o que nos obrigou a substituir um ponto de inquérito previsto (Urubu-Ka’apor), o que, por sua vez, atrasou a coleta de dados no ponto substituto (Anambé). Em todos os pontos de inquérito pesquisados, foi um desafio entrar em contato com as lideranças indígenas para conseguir autorização de acesso, fator que por si só constitui uma inovadora fronteira para a realização de estudos geolinguísticos no Brasil, que em geral são realizados em comunidades sem restrições legais de acesso.

Outro fator que emergiu do contexto de pesquisa foi justamente o fato de as terras indígenas estudadas constituírem espaços bilíngues ou plurilíngues, uma vez que, além da língua portuguesa, os indígenas pertencentes às etnias estudadas, por vezes, dominavam

\footnotetext{
${ }^{1}$ Que também inclui outros estudos desenvolvidos no projeto GeoLinTerm/UFPA, como dissertações e projetos de tese que estão mapeando o português de contato com línguas indígenas em áreas indígenas dos estados do Pará, Amapá e Amazonas.

${ }^{2}$ Agregado ao projeto do Atlas Línguístico Sonoro das Línguas Indígenas do Brasil (UnB/UFPA).

${ }^{3}$ Campo no qual destacamos a valiosa contribuição de pesquisadores do LaLLi da UnB.
} 
mais de uma língua indígena, o que nos levou à necessidade de incluir o mapeamento da variável dialingual no estudo realizado.

Também necessitou de adaptação metodológica o controle do tempo utilizado para coleta de dados. Fomos orientados a sermos cautelosos na abordagem dos indígenas para a seleção de colaboradores e nas entrevistas, o que demandou um tempo maior em relação às nossas experiências pregressas na pesquisa de campo em geolinguística, em áreas monolíngues, nas quais não se têm, por exemplo, barreiras linguísticas ocasionadas pelo grau de bilinguismo do colaborador, ou pelo tempo necessário para a boa aceitação do inquiridor na comunidade. O desafio nesse aspecto foi, levando em consideração esses fatores, acelerar o processo de seleção de colaboradores e de coleta de dados em vista da coleta a ser realizada nos demais pontos de inquérito previstos no projeto. A média de tempo de cada incursão a campo nas áreas indígenas foi de 10 a 15 dias, sendo necessárias duas ou três incursões em alguns dos pontos de inquérito.

Outro aspecto metodológico adaptado foi a substituição da nomenclatura "informante". Optamos por utilizar a nomenclatura "colaborador" para definir a fonte da informação na pesquisa. Nossa opção se deu em função de uma carga semântica negativa imposta ao termo "informante" no âmbito da pesquisa científica com indígenas. Em função do contexto sócio-histórico de contato e exploração dos povos indígenas brasileiros, no âmbito da pesquisa científica permaneceu por gerações de pesquisadores um tratamento pormenorizado dos colaboradores no fazer científico; estes últimos eram tratados como meros fornecedores de informações sobre as suas etnias, suas culturas, as línguas que falam, os ambientes em que vivem, a natureza, o clima, os acidentes geográficos etc. Entendemos, por outro lado, que o papel do colaborador vai além dessa postura passiva, mas se materializa como uma colaboração indispensável à pesquisa de campo geossociolinguística, que é melhor representado por um processo colaborativo, no qual inquiridores e os colaboradores cooperam para o registro de dados e a construção do conhecimento científico.

Os colaboradores do projeto ALiPAI são selecionados de acordo com os seguintes parâmetros: dez colaboradores por ponto de inquérito. Em relação ao fator idade, os colaboradores se enquadram em três faixas etárias: $1^{\mathrm{a}}$ - de 5 a 10 anos; $2^{\mathrm{a}}$ - de 18 a 37 anos; e $3^{a}$ - de 47 a 75 anos, de forma a se mapear a representação de falantes mais jovens e de mais velhos. Em relação ao gênero, foram selecionadas duas crianças (um menino e uma menina), dois homens e duas mulheres na segunda faixa etária, e dois homens e duas mulheres na terceira faixa etária para cada localidade, o que constitui uma inovação entre os estudos dialetológicos brasileiros de que se tem conhecimento, uma vez que não se tem, tradicionalmente, levado em consideração a fala de crianças, o que aqui foi feito em função tanto da variação linguística, quanto da verificação do grau de bilinguismo nas comunidades indígenas.

Contemplando-se a variável diastrática, em cada localidade foram entrevistados colaboradores em dois níveis de escolaridade. No primeiro nível enquadraram-se dois homens e duas mulheres com escolaridade menor ou igual ao $9^{\circ}$ ano do ensino fundamental, e dois 
homens e duas mulheres com escolaridade maior ou igual ao $1^{\circ}$ ano do ensino médio (incluindo-se, portanto, os indígenas que possuem nível superior completo ou incompleto, como os cursos de licenciatura intercultural).

Com relação às duas crianças representantes de cada etnia, o fator escolaridade foi desprezado, uma vez que todas as crianças selecionadas estão regularmente matriculadas nas escolas das aldeias. O mapeamento da fala dessas crianças contribuiu para a quantificação dos dados geossociolinguísticos no que se refere à variação fonética do português, ao grau de bilinguismo e aos comportamentos linguísticos dos colaboradores em relação ao português e às línguas indígenas de cada etnia.

A abordagem pluridimensional adotada no ALiPAI exigiu a elaboração de cartas linguísticas que registrassem concomitantemente as variáveis consideradas (diatópica, diagenérica, diageracional, diastrática e dialingual ${ }^{4}$ ), como a carta seguinte (Figura 2):

Figura 2 - Carta D01 - Denominações registradas em LI para "rato"

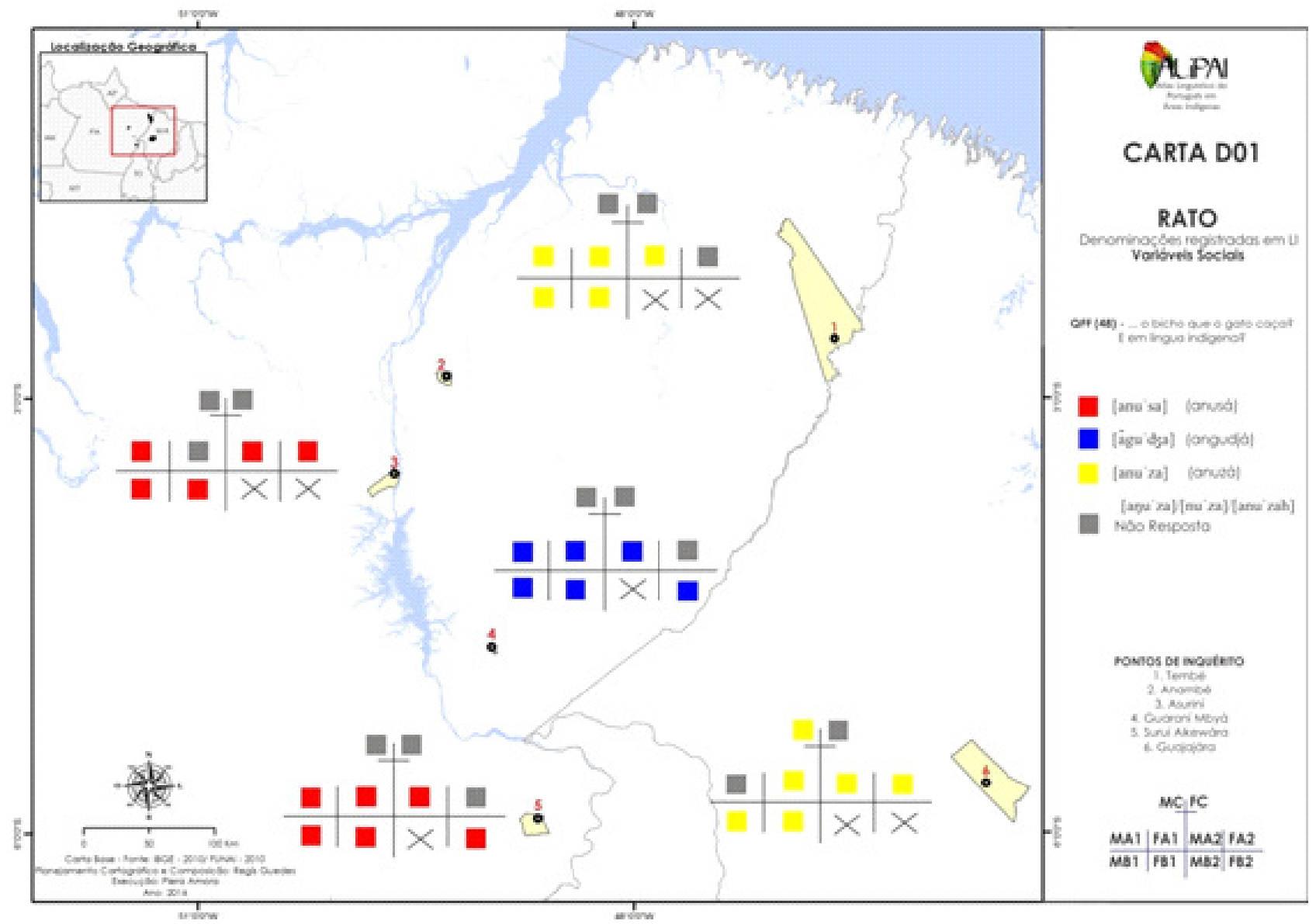

Fonte: Guedes (2017).

${ }^{4}$ A variável diarreferencial, também considerada no estudo de Guedes (2017), foi mapeada separadamente, seguindo outros recursos cartográficos. 
Na carta D01 (Figura 2) foram mapeadas as respostas obtidas sobre o item "rato" nas cinco línguas indígenas das comunidades estudadas - 1. Tembé; 3. Asuriní; 4. GuaraníMbya; 5. Suruí Aikewára; e 6. Guajajára). Os dados mapeados nessa carta dialingual confirmam a classificação de Rodrigues e Cabral (2012) para as relações de parentesto dessas línguas dentro da família Tupí-Guaraní. Como se pode observar na Figura 2, as línguas Asuriní do Tocantins (ponto 3) e Suruí Aikewára (ponto 5) são muito próximas e comungam de uma mesma lexia: [anu'sa] para definir "rato". Como afirmam Laraia e Matta (1967), trata-se de dois povos que outrora constituíram um mesmo sistema cultural. O mesmo processo é observado entre os Tembé (ponto 1) e o Guajajára (ponto 6), cuja lexia registrada [anu'za] e suas variantes fonéticas [ạu'za], [nu'za] e [anu'zah] são muito similares, guardando entre si a pronúncia da fricativa alveolar sonora [z], em contraste com os Suruí e os Asuriní que apresentam a realização fricativa surda [s]. Para Rodrigues e Cabral (2012), o Tembé e o Guajajára constituem dois ramos (o ocidental e o oriental, respectivamente) da língua Tenetehára. Já entre os Guaraní-Mbyá, obtivemos o registro de [ãgu'dza]. Os dados mapeados na Carta D01 demonstram uma tendência entre essas línguas indígenas para a variação entre esses sons [s, z e d3], variação esta que também está presente no português falado por esses indígenas, especialmente na fala dos colaboradores mais velhos, como rastros de influências do substrato linguístico de matriz tupí-guaraní (GUEDES, 2017).

Essas adaptações metodológicas realizadas propiciaram um mapeamento geolinguístico eficiente do português em contato com essas cinco línguas indígenas. Este modelo desenvolvido tem servido de referência para os demais estudos que estão sendo realizados no âmbito do projeto ALiPAI em outras terras indígenas dos estados do Amapá e do Amazonas.

A coleta de dados do ALiPAI está sendo realizada por meio da aplicação de três questionários: (i) Questionário Sociolinguístico (QS), que tem por finalidade identificar a situação sociolinguística da comunidade em relação ao grau de bilinguismo e aos comportamentos linguísticos dos falantes em relação às línguas faladas na comunidade (português e línguas indígenas); (ii) Questionário Fonético-Fonológico (QFF), que é orientado principalmente, mas não exclusivamente, no sentido de identificar as áreas em que ocorrem fatos fônicos já documentados para o português em pesquisas anteriores; (iii) Questionário Fonético-Fonológico Complementar (QFFC), elaborado a partir de fenômenos de influência fonético-fonológica, descritos por Silva (2010), com vistas a registrar as possíveis influências do substrato de origem Tupí-Guaraní no português falado pelos indígenas das etnias em questão.

O Questionário Sociolinguístico foi elaborado a partir de consultas a outras pesquisas em Geolinguística Pluridimensional e Contatual, como a tese de Margotti (2004), e de questões elaboradas pela equipe do projeto GeoLin'Term.

Os questionários QFF e QSL aplicados na pesquisa de campo do ALiPAI foram elaborados pela equipe do Atlas Linguístico do Brasil (COMITÊ..., 2001); porém, foram adaptados da seguinte forma: após cada pergunta foi adicionada a indagação "... e na sua língua, como se chama isso?", no intuito de registrar o conhecimento lateral de línguas indígenas pelo colaborador. Ao final do QSL, também foi acrescentada uma solicitação para que os 
colaboradores adultos fizessem um Relato de Experiência Pessoal, que poderia ser a narração de um fato ocorrido ou de uma história tradicional daquele povo, em língua portuguesa e, posteriormente, na língua indígena própria da etnia investigada.

Objetivando-se investigar mais amplamente a variação lexical e fonética do português falado pelos colaboradores, adotou-se o método "passo triplo", ou "pesquisa em três tempos" de Radtke e Thun (1996), que consiste na observância de três etapas na aplicação dos questionários: perguntar, insistir e sugerir.

Em vista das testagens dos questionários, decidiu-se por utilizar, sempre que necessário (especialmente com as crianças e idosos), os questionários QFF e QSL ilustrados, que por limitação própria dessa metodologia, não contemplou alguns itens de conteúdo abstrato ou constituídos por processos: "obrigado" (QFF - 79) ou "fanhoso" (QSL - 101).

A cartografia dos dados mapeados está sendo feita por meio dos softwares editores de imagem Photoshop e CorelDRAW. O mapa base foi gerado a partir do programa de georreferenciamento ArcGIS.

A coleta de dados está sendo realizada in loco, por meio de entrevistas gravadas com gravadores digitais profissionais das marcas Sony, Tascam e Zoom, no intuito de registrar com alta qualidade os arquivos sonoros para compor o banco de dados do projeto ALiPAI.

\section{Considerações Finais}

A aplicação dos questionários nessas primeiras experiências de pesquisa de campo em áreas indígenas pode ser avaliada como satisfatória, apesar das condições físicas e acústicas dos ambientes e de situações de gravação, que nem sempre eram silenciosas, e do índice de não respostas obtido para algumas questões, como as do campo semântico "Vida Urbana" do QSL do ALiB, o que parece refletir o não pertencimento de alguns itens lexicais ao universo semântico das comunidades até o momento estudadas.

Das adaptações metodológicas realizadas para a coleta de dados no ALiPAI, nossas primeiras impressões nos fazem concluir que ambas foram muito produtivas. Especialmente a inclusão da variável diastrática (escolaridade) (adaptada do Projeto ALiB), considerando colaboradores mais escolarizados os com escolaridade a partir do $1^{\circ}$ ano do ensino médio ao ensino superior, no intuito de não desprezar essa variável que está em processo de expansão nas comunidades indígenas, a partir do crescente acesso de indígenas ao ensino médio e superior.

Por outro lado, consideramos de suma importância a inclusão das duas crianças $\left(1^{\mathrm{a}}\right.$ faixa etária) como colaboradores na pesquisa. Essa escolha possibilitou ratificar o que demonstraram outros estudos ${ }^{5}$ que já assinalaram a baixa vitalidade das línguas indígenas

\footnotetext{
${ }^{5}$ Carvalho (2001), Cabral, Negreiros e Simão (2006), Silva (2010), Lopes (2014) e relatório da UNESCO (2011), que classifica como "Vulnerável” as línguas Asuriní do Tocantins, Suruí Aikewára, Guajajára e Guananí Mbyá, e como "Definitivamente em perigo” à língua Tembé.
} 
dessas etnias, que são classificadas como "ameaçadas de extinção", o que está diretamente relacionado à difusão da língua portuguesa entre as gerações mais jovens $\left(1^{\mathrm{a}}\right.$ e $2^{\mathrm{a}}$ faixas etárias) nas áreas indígenas estudadas.

\section{REFERÊNCIAS}

ATLAS UNESCO de las lenguas del mundo en peligro. 2011. Disponível em: <https://bit.ly/1JVCiLM>. Acesso em: 15 ago. 2016.

CABRAL, A. S. A. C.; NEGREIROS, D. A.; SIMÃO, R. N. Relatório sobre a pesquisa realizada na Terra Indigena Trocará com vistas à caracterização da situação de Vitalidade da Lingua Asurini do Tocantins. 2006. (Relatório de Pesquisa).

CARVALHO, M. G. P. Sinais de morte ou de vitalidade? Mudanças estruturais na língua Tembé. 2001. Dissertação (Mestrado em Letras) - Universidade Federal do Pará, Belém.

COMITÊ NACIONAL DO PROJETO ALIB. Atlas Lingüistico do Brasil: questionários 2001. Londrina: Ed. UEL, 2001.

CARDOSO, S. A. M. et al. Atlas Linguístico do Brasil. Introdução. Londrina: Eduel, 2014. v. 1.

GUEDES, R. J. C. Estudo geossociolinguístico da variação lexical na zona Rural do estado do Pará. 2012. Dissertação (Mestrado em Letras) - Universidade Federal do Pará, Belém.

GUEDES, R. J. C. Perfil geossociolinguístico do português em contato com linguas tupi-guaraní em áreas indígenas dos estados do Pará e Maranbão. 2017. Tese (Doutorado em Letras) Universidade Federal do Pará, Belém.

LARAIA, R. de B.; MATTA, R. da. Índios e Castanheiros: a empresa extrativa e os índios no médio Tocantins. São Paulo: Difusão Européia do Livro, 1967.

LOPES, J. D. Uma interface da documentação linguística e modelos lexicográficos para línguas indigenas brasileiras: uma proposta para o Suruí-aikewára. 2014. Tese (Doutorado em Linguística) - Universidade de Brasília, Brasília.

MARGOTTI, F. W. Difusão sócio-geográfica do português em contato com o italiano no Sul do Brasil. 2004. Tese (Doutorado em Letras) - Universidade Federal do Rio Grande do Sul, Porto Alegre. 
RADTKE, E.; THUN, H. Neue Wege der romanischen Geolinguistik: Eine Bilanz. In: RADTKE; E.; THUN, H. (Ed.). Neue Wege der romanischen Geolinguistik: Akten des Symposiums zur empirischen Dialektologie. Kiel: WestenseeVerl., 1996. p. 1-24.

RAZKY, A. O Atlas geo-sociolingüístico do Pará: abordagem metodológica. In: AGUILERA, V. de A. (Org). A Geolingüistica no Brasil: caminhos e perspectivas. Londrina: Ed. UEL, 1998. p. 155-164.

RAZKY, A.; GUEDES, R. J. C. Le continuum des regroupements lexicaux dans l'atlas géosociolinguistique du Pará. Revista Géoliguistique, n. 15, p. 149-162, 2015.

RODRIGUES, A. D. Os cenários da chegada da língua portuguesa. In: CARDOSO, S. A. M.; MOTA, J. A.; MATTOS E SILVA, R. V. Quinhentos anos de história lingïística do Brasil. Salvador: Secretaria da Cultura e Turismo do Estado do Bahia, 2006. p. 143-161.

RODRIGUES, A. D. On the influence of indigenous languages on Brazilian Portuguese. DELTA, v. 30, n. esp., p. 443-463, 2014.

RODRIGUES, A. D.; CABRAL, A. S. A. C. Tupían. In: CAMPBELL, L.;

GRONDONA, V. (Org.). The indigenous languages of South America. Berlin; Boston: Mouton de Gruyter, 2012. v. 2. p. 495-574.

SILVA, T. F. da. História da lingua tenetehára: contribuição aos estudos histórico-comparativos sobre a diversificação da família linguística tupi-guarani do tronco tupí. 2010. Tese (Doutorado em Linguística) - Universidade de Brasília, Brasília.

THUN, H. La geolingüística como lingüística variacional general (con ejemplos del Atlas linguístico Diatópico y Diastrático del Uruguay). In: RUFFENO, G. (Ed.). International Congress of Romance Linguistics and Pbilology. Tübingen: Niemeyer, 1998. p. 701-730.

THUN, H. Entrevista concedida no III Congresso Internacional de Dialetologia e SociolinguísticaIII CIDS. Londrina, 2014. Áudio digital. (Não publicado).

ZÁGARI, M. R. L. Os falares mineiros: esboço de um Atlas Lingüístico de Minas Gerais. In: AGUILERA, V. de A. (Org.). A Geolingüistica no Brasil: caminhos e perspectivas. Londrina: Ed. UEL, 1998. p. 31-77. 